\title{
Title: Deficient goal-directed control in a population characterized by extreme goal pursuit
}

\author{
Authors: Karin Foerde ${ }^{1,2}$, Nathaniel D. Daw ${ }^{3}$, Teresa Rufin ${ }^{1}$, B Timothy Walsh ${ }^{1,2}$, Daphna \\ Shohamy ${ }^{4}$, Joanna E. Steinglass ${ }^{1,2}$
}

\begin{abstract}
Affiliations:
${ }^{1}$ New York State Psychiatric Institute

${ }^{2}$ Columbia University Irving Medical Center, Department of Psychiatry

${ }^{3}$ Princeton Neuroscience Institute and Department of Psychology, Princeton University

${ }^{4}$ Department of Psychology, Zuckerman Mind, Brain, Behavior Institute, Kavli Institute for Brain Science
\end{abstract}

Correspondence to: Karin Foerde (kf2265@columbia.edu) 


\begin{abstract}
Computational neuroscience has contributed to understanding compulsive behavior by distinguishing habitual from goal-directed choice through model-free and model-based learning. Yet, questions remain about applying this approach to psychiatric conditions that are characterized by complex behaviors that occur outside the laboratory. Here, we compared individuals with anorexia nervosa (AN), whose self-starvation appears both excessively goaldirected and habitual, with healthy controls (HC) to assess: 1) whether their behavior is characterized by enhanced or diminished model-based behavior, 2) the domain specificity of any abnormalities by comparing learning in a food-specific context as well as in a monetary context, and 3) whether impairments are secondary to starvation by comparing learning before and after initial treatment. Across all conditions, individuals with AN showed an impairment in model-based, but not model-free, learning, suggesting a general and persistent contribution of habitual over goal-directed control, across domains and timepoints.
\end{abstract}




\section{INTRODUCTION}

The pathophysiology of psychiatric illnesses is poorly understood. Little is known about etiologies, diagnostic tests mainly serve to rule out medical illness, and underlying neural mechanisms remain mysterious. These problems stem, in part, from the great challenge of understanding the mechanisms of mental processes even in the healthy brain. Recent advances in cognitive and computational neuroscience offer promising new approaches for understanding brain mechanisms underlying psychiatric symptoms (Huys, Maia, \& Frank, 2016). For example, the emerging understanding of the brain's systems for habitual vs. goal-directed control has offered a potential mechanism underlying compulsive symptomatology (Everitt \& Robbins, 2016), which can occur across a range of psychiatric illnesses. In the present study, we apply methods for probing habitual versus goal-directed behavior in relation to anorexia nervosa (AN), in which the central behavioral feature appears to be both extremely goal-focused (unrelenting pursuit of thinness) and yet rigidly unchangeable (poor responses to treatment) (Walsh, 2013), thereby challenging a simple automatic-vs-controlled dichotomy.

The existence of a dichotomy between automatic and controlled behavior is a long-standing organizing principle in psychology and neuroscience (James, 1890), and recent research shows that controlled or goal-driven, motivated behaviors can be distinguished behaviorally and neurally from cue-elicited, automatic behaviors ("habits") (Dickinson \& Balleine, 2002; Graybiel, 2008). These two types of behavior have been argued to arise from distinct computational mechanisms for evaluating actions, known as model-based and model-free learning (Daw, Gershman, Seymour, Dayan, \& Dolan, 2011; Daw, Niv, \& Dayan, 2005). Goal-directed (or model-based) behavior enables pursuit of long-term goals, even if there is conflict with shortterm temptations, and its deliberative nature offers the ability to update behavior when the value of an outcome changes. Habitual (or model-free) behavior results from repetition of stimulusresponse associations and facilitates efficient automatic behavior in response to cues but renders behavior relatively inflexible. In the lab, these approaches can be distinguished using instrumental learning tasks that include outcome devaluation procedures and two-step Markov decision tasks, and are associated with partially distinct neural substrates (Coutureau \& Killcross, 2003; Daw et al., 2011; Glascher, Daw, Dayan, \& O'Doherty, 2010; Killcross \& Coutureau, 2003; Lee, Shimojo, \& O'Doherty, 2014; Tricomi, Balleine, \& O'Doherty, 2009; Valentin, Dickinson, \& O'Doherty, 2007; Yin, Knowlton, \& Balleine, 2004; Yin, Knowlton, \& Balleine, 2006). 
Experimental evidence shows that healthy people generally use a mix of both model-free and model-based approaches, shifting the balance between them depending on circumstances (Daw et al., 2011; Otto, Gershman, Markman, \& Daw, 2013; Otto, Raio, Chiang, Phelps, \& Daw, 2013; Weissengruber, Lee, O'Doherty, \& Ruff, 2019). In contrast, reductions in model-based, goal-directed behavior have been shown in disorders with compulsive behaviors, such as obsessive compulsive disorder (OCD) and binge eating disorder (Gillan et al., 2015; Gillan, Robbins, Sahakian, van den Heuvel, \& van Wingen, 2016; Voon et al., 2015). Together, these studies suggest that a computational approach that distinguishes the contributions of habitual and goal-directed behavior may help link psychiatric symptoms with dysfunction in basic neural mechanisms.

Compulsive behavior, broadly, is action engaged in persistently, even when unrewarding or maladaptive, and often despite an individual's own assessment that it is excessive. Multiple psychiatric disorders are characterized by behaviors with a seemingly compulsive character (e.g., tic disorders, obsessive-compulsive disorder, substance use disorders, and eating disorders; American Psychiatric Association, 2013) and the persistence of these varied compulsive behaviors is puzzling. One hypothesis is that excessive relative dominance of automatic behavior underlies compulsivity (Everitt \& Robbins, 2016; Gillan et al., 2015; Gillan \& Robbins, 2014). However, some basic questions remain about the adequacy and explanatory potential of this framework for elucidating mechanisms of psychiatric illness, three of which we address in the current study.

First, a range of psychiatric illnesses include behaviors that can be considered compulsive, but the behaviors themselves are not always easily captured by the simple, repetitive, stimulusevoked habits described in the experimental literature. That is, categorizing the real-world behaviors at the core of psychiatric illnesses is complex. For example, engagement in a ritualized behavior to reduce anxiety symptoms in OCD may, in some ways, be compulsive and automated, yet it can also be construed as a successful, goal-directed, strategy for managing anxiety due to obsessions (Salkovskis, 1985). Similarly, drug-seeking behavior may be compulsive, and at the same time require considerable flexible goal pursuit (Tiffany, 1990).

AN provides a particularly intriguing example. Maintenance of significantly low body weight is a defining feature of AN (American Psychiatric Association, 2013). This self-starvation appears to 
be an unrelenting goal pursuit focused on weight loss, and individuals with AN are commonly thought of as rigidly self-controlled (Bruch, 1979). Data from temporal discounting studies show that individuals with AN are more likely than healthy comparison participants to forego immediate monetary rewards in favor of larger, delayed rewards during intertemporal choices, consistent with descriptions of heightened self-control (Decker, Figner, \& Steinglass, 2015; Steinglass et al., 2012; Steinglass et al., 2017). And yet, the restrictive eating that characterizes AN also shares many features of habit (Foerde, Steinglass, Shohamy, \& Walsh, 2015; Walsh, 2013): it is learned (not innate), is inflexibly triggered by certain cues, and individuals with AN are unable to readily change this behavior - even when seeking treatment, suggesting that it has become outcome-independent over time. The possibility that persistent maladaptive choices in AN may reflect overlearned habits is particularly intriguing given that the behavior is characterized by choices against normatively rewarding foods (e.g. foods high in sugar and fat). Thus, it remains unclear whether maladaptive behavior in AN reflects excessively goal-directed or excessively habitual behavioral control. More operationally, the question remains: if behavior in AN arises from imbalance between goal-directed and habitual mechanisms, which one is dominant?

Second, goal-directed and habitual behavior are domain-general mechanisms, as illustrated by their trans-diagnostic application, yet, different psychiatric illnesses involve quite specific compulsive behaviors (e.g., OCD with specific compulsions, abuse of specific substances, gambling, or excessive weight loss). Most, if not all, laboratory studies have used generic outcomes, typically money (Gillan et al., 2016; Voon et al., 2015) or food (Tricomi et al., 2009; Valentin et al., 2007), to study goal-directed and habitual behavior. An important interpretational question left open by these studies is whether apparent deficits in goal-directed control in psychiatric patients are due to impairments in a domain-general mechanism, or instead to a reorienting of goal-directed behavior toward the object of compulsion at the expense of other domains. The latter view would predict that substance abusers, for instance, are relatively unmotivated by money (and unwilling to pursue it with goal-directed control) but could mitigate or even reverse their impairment if their drug of abuse was at stake. Similarly, for individuals with AN, the balance of model-based and model-free control may be different for choices about money than for choices about food. Thus, does psychopathology reflect a domain-general deficit in goal-directed (model-based) learning, or something more outcome-specific? Whereas studying many illness-specific outcomes (including drugs of abuse) in the lab comes with 
obvious challenges, studying AN offers an opportunity to address this question via tasks in the setting of food outcomes compared with money outcomes.

Third, the presence of model-based deficits in the setting of psychiatric illness only indicates a correlation between the two and does not directly support the presumption that imbalanced learning is a causal factor in developing maladaptive compulsions. Indeed, decreased goaldirected control may be a result of compulsive behaviors, as has been argued, for instance, for neurological effects of drugs of abuse (Volkow et al., 2010). Overall, little is known about the longitudinal progression of these deficits. For instance, are deficits in goal-directed control remediated by treatment of psychopathology in disorders of compulsion? If deficits are remediated, this would suggest that they are an acute symptom of the disorder, and likely not a pre-existing cause. A recent study suggested that impairments in goal-directed behavior in OCD are not remediated by cognitive behavioral therapy (Wheaton, Gillan, \& Simpson, 2018). For AN particularly, the secondary effects of starvation on cognition might be substantial. Thus, by studying individuals with AN during acute illness and again after extensive inpatient weightrestoration treatment, the persistence of any learning differences and their relation to changes in psychopathology can be assessed.

In this study we addressed these questions with a population of individuals with AN using a twostep Markov decision task (Figure 1) designed to assess the extent of model-based vs. modelfree learning. By examining an illness with complex and seemingly highly controlled (yet maladaptive) behaviors, we aimed to test whether these reflect heightened or deficient modelbased behavior. We also compared results from food and monetary versions of the task to examine the specificity of findings in the eating disorder domain and tested for the presence of model-based vs. model-free behavior in the context of outcomes directly relevant to underlying psychopathology. Whereas the monetary task assumes that money is rewarding, in the food task participants were rewarded with points that they could use to select the food of their choice, thereby allowing the food-relevant task to be motivationally relevant to both controls and patients. Finally, we evaluated patients before and after inpatient weight-restoration treatment, to begin to study the progression of model-based and model-free processes. 

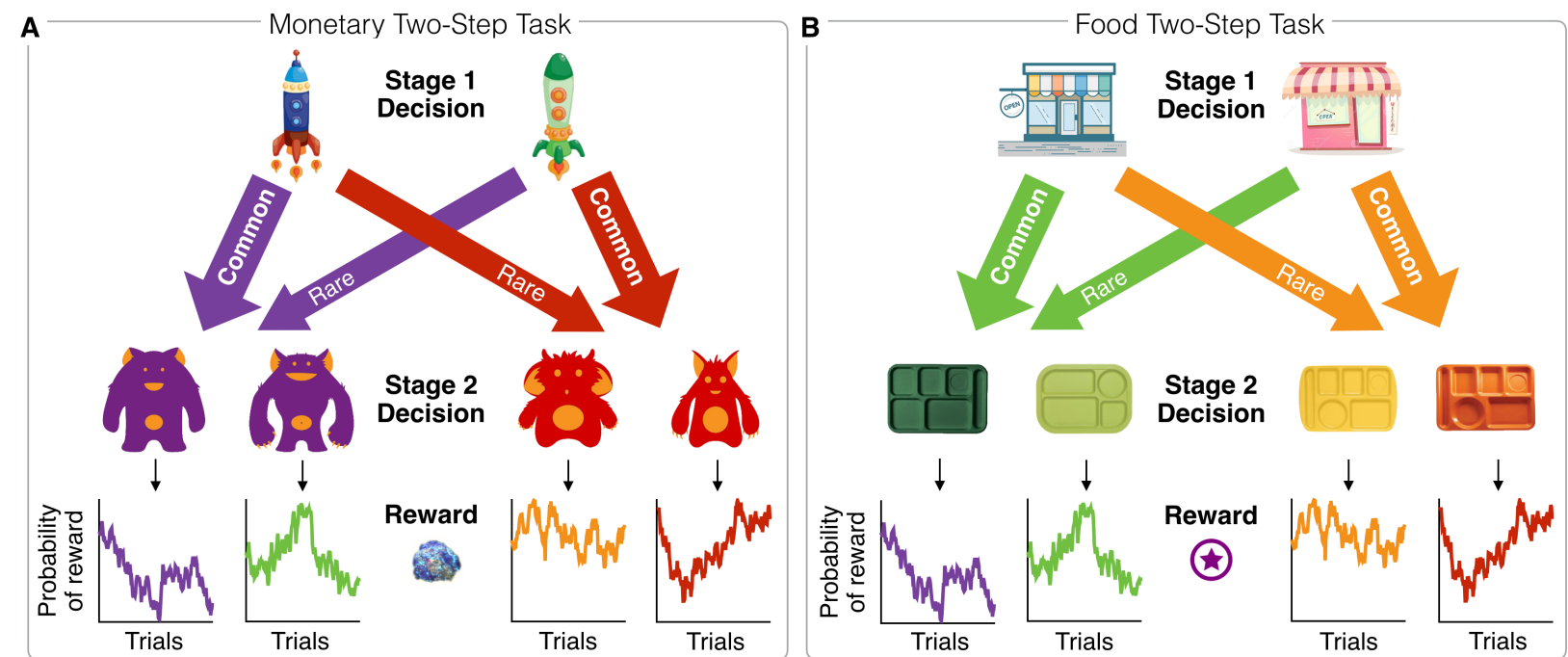

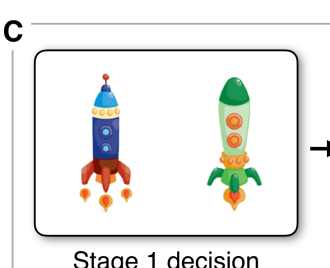

Stage 1 decision $(<3 s)$

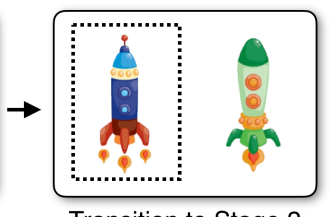

Transition to Stage 2

(2.5 s)

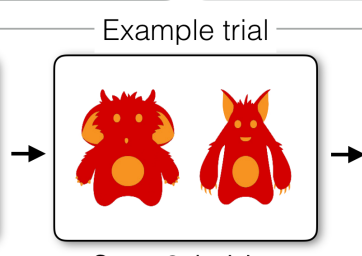

Stage 2 decision $(<3 \mathrm{~s})$

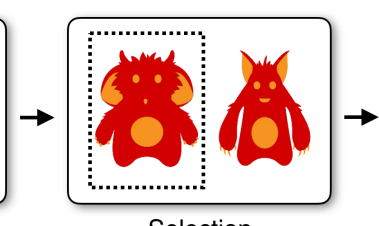

Selection

(2.5 s)

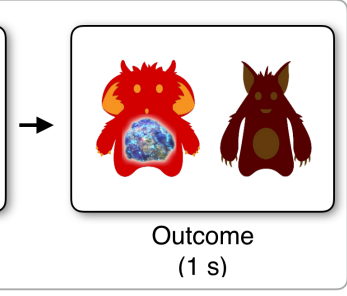

Outcome

Figure 1. Two-step decision tasks used to assess model-free and model-based learning. A) Decision task with monetary outcomes. Alien treasure pieces were converted into a monetary bonus at the end of the task. B) Task with food outcomes. Food tokens were converted into access to a range of preferred snack items and the selected snack was consumed after the task. (A, B) In both tasks, the Stage 1 choice determined the transition to the next stage according to a fixed probability. One choice was associated with transition to one particular Stage 2 state $70 \%$ of the time (Common transition) and the other state $30 \%$ of the time (Rare transition). At Stage 2, participants made choices followed by reward or no reward (both monetary and food outcomes were actualized after the task). Each Stage 2 option was associated with a probabilistic reward, which ranged from $0.25-0.75$ and varied gradually (according to a Gaussian random walk) and independently across trials (see examples in bottom rows of $\mathbf{A}$ and $\mathbf{B})$. C) Example trial steps from the monetary task.

\section{RESULTS}

As expected, the $\mathrm{HC}$ and $\mathrm{AN}$ groups differed on measures of eating disorder severity (Eating Disorder Examination Questionnaire, EDEQ; (Fairburn, 2008; Fairburn \& Beglin, 1994)), depression (Beck Depression Inventory, BDI; (Beck \& Steer, 1993)), anxiety (State-Trait Anxiety Inventory, STAl; (Spielberger, Gorsuch, \& Lushene, 1970)), and body mass index (BMI) at Time 1, but did not differ on age (see Table 1). Although all participants had IQ scores in the normal range, there was a statistically significant group difference; IQ (which has been associated with model-based learning in previous studies; (Gillan et al., 2016)) was included as a covariate in all analyses. Additionally, age was included as a covariate, as the sample spanned adolescents and adults and use of model-based learning has been shown to develop gradually across 
adolescence (Decker, Otto, Daw, \& Hartley, 2016). Mean BMI increased significantly from Time 1 to Time 2 among individuals with $\mathrm{AN}(\mathrm{t}(23)=-13.01, \mathrm{p}<0.001)$ and did not differ significantly between groups at Time 2, indicating successful weight restoration among individuals with AN. In addition, among individuals with AN, the expected psychological change was seen as measures of eating disorder pathology (EDEQ: $t(24)=6.7, p<0.001)$, depression (BDI: $t(23)=5.15, p<0.001)$, and anxiety (STAl: $t(24)=3.36, p=0.003)$, significantly improved from Time 1 to Time 2, although these measures remained elevated relative to $\mathrm{HC}$ (ps $<0.001$, see Table 1).

Table 1. Demographic and clinical information

\begin{tabular}{|c|c|c|c|c|c|c|c|c|}
\hline & \multicolumn{4}{|c|}{ Time 1} & \multicolumn{4}{|c|}{ Time 2} \\
\hline & $H C(n=53)$ & AN $(n=41)$ & & & $H C(n=29)$ & AN $(n=25)$ & & \\
\hline & Mean \pm SD & Mean \pm SD & $t$ & $p$ & $\begin{array}{l}\text { Mean } \pm \\
\text { SD }\end{array}$ & Mean \pm SD & $t$ & $p$ \\
\hline Age (years) & $25.6 \pm 5.0$ & $27.1 \pm 7.0$ & 1.2 & 0.236 & & & & \\
\hline WASI Est. IQ & $111.8 \pm 12.2$ & $105.1 \pm 11.3$ & -2.7 & 0.008 & & & & \\
\hline BMI $\left(\mathrm{kg} / \mathrm{m}^{2}\right)$ & $21.3 \pm 1.5$ & $16.0 \pm 2.0$ & -14.6 & $<0.001$ & $20.9 \pm 1.3$ & $20.4 \pm 0.9$ & -1.4 & 0.172 \\
\hline Dur. III. (years) & $\mathrm{n} / \mathrm{a}$ & $9.6 \pm 7.1$ & & & & & & \\
\hline EDEQ & $0.5 \pm 0.6$ & $4.16 \pm 1.5$ & 15.8 & $<0.001$ & $0.4 \pm 0.4$ & $2.8 \pm 1.2$ & 9.8 & $<0.001$ \\
\hline BDI & $2.1 \pm 2.4$ & $27.6 \pm 12.6$ & 14.4 & $<0.001$ & $3.0 \pm 2.6$ & $18.0 \pm 14.0$ & 5.7 & $<0.001$ \\
\hline STAI (T) & $31.3 \pm 7.3$ & $61.0 \pm 11.2$ & 15.5 & $<0.001$ & $33.6 \pm 8.7$ & $56.4 \pm 12.4$ & 7.9 & 0.003 \\
\hline YBC-EDS Total & $\mathrm{n} / \mathrm{a}$ & $22.5 \pm 6.4$ & & & & & & \\
\hline Preocupation & $\mathrm{n} / \mathrm{a}$ & $11.7 \pm 3.2$ & & & & & & \\
\hline Rituals & $\mathrm{n} / \mathrm{a}$ & $10.8 \pm 3.7$ & & & & & & \\
\hline
\end{tabular}

AN: anorexia nervosa; BDI: Beck Depression Inventory; BMI: body mass index; Dur. III: duration of illness; EDEQ: Eating Disorder Examination questionnaire; HC: healthy comparison participant; STAI(T): StateTrait Anxiety Inventory; YBC-EDS: Yale-Brown-Cornell Eating Disorder Scale; WASI: Wechsler Abbreviated Scale of Intelligence. WASI IQ data are missing from 1 AN. At Time 1, BDI data are missing from 1 AN. At Time 2, BMI data are missing from 1 AN.

To examine task performance, we first tested whether individuals with AN differed from $\mathrm{HC}$ in model-free and model-based learning overall, across both monetary and food outcome versions at both assessment points (modeling any effects of task and session but considering first the main effect of group). There was a significant contribution of model-free learning to behavior in both groups (ps < 1e-5) and no significant difference between groups (Est: 0.09, SE =0.06, z = 1.36, $\mathrm{p}=0.174$; Fig. 2). In contrast, model-based learning was also present in both groups (ps < 1e-5) but significantly attenuated in the AN group relative to the HC group (Est: 0.15 , SE = $0.06, z=2.27, p=0.023$; Fig. 2). To test the specificity of the group difference to model-based relative to model-free learning, we repeated the analysis using the parameter $w$ (see Methods), 
which measures the relative reliance on model-based learning and found that the relative reliance $w$ was increased among $\mathrm{HC}$ (Est: $0.41, \mathrm{SE}=0.2, \mathrm{z}=2.06, \mathrm{p}=0.039$ ).

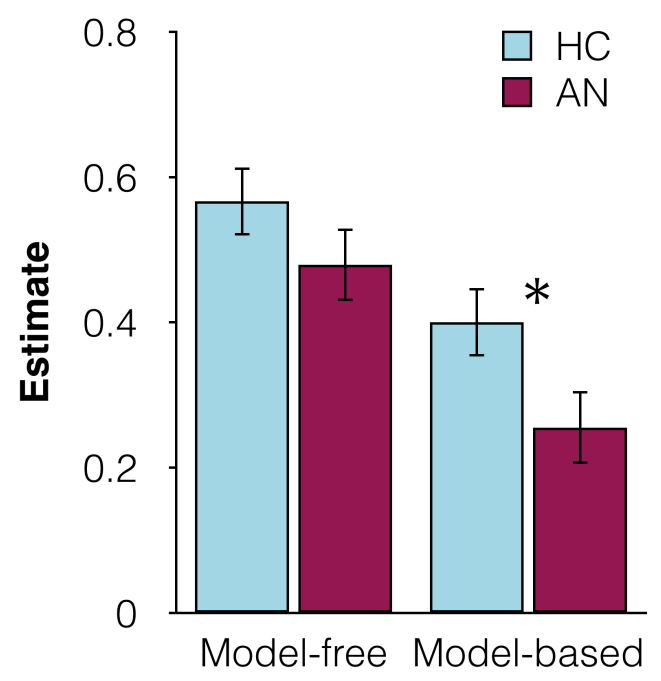

Figure 2: Overall model-free and modelbased contributions to learning for $\mathrm{HC}$ and $\mathrm{AN}$ across task type (monetary and food) and session (Time 1 and Time 2).

Next, we tested whether the model-based deficit was domain-general or specific to monetary vs. food outcomes (Table 2). Task type did not interact significantly with group differences in model-based learning (Est: $-0.08, \mathrm{SE}=0.07, z=-1.11, \mathrm{p}=0.27$ ) and the same pattern of impaired model-based learning in AN was observed regardless of outcome (Fig. 3A). There was, however, a main effect of task such that all participants showed a greater model-based contribution in the monetary task relative to the food outcome task (Est: $0.15, \mathrm{SE}=0.05, \mathrm{z}=$ 2.78, $p=0.006)$.

Table 2. Model based learning: regression analysis including Group, Session, and Task type

\begin{tabular}{lccc}
\hline & Estimate (SE) & z-value & p-value \\
\hline Intercept & $0.25(0.05)$ & 4.74 & $<1 \mathrm{e}-5$ \\
Group & $0.16(0.07)$ & 2.26 & 0.024 \\
Session & $0.09(0.06)$ & 1.44 & 0.150 \\
Task type & $0.15(0.05)$ & 2.78 & 0.006 \\
IQ (z-scored) & $0.05(0.03)$ & 1.46 & 0.145 \\
Age (z-scored) & $0.00(0.03)$ & -0.08 & 0.934 \\
Group x Session & $0.02(0.08)$ & 0.27 & 0.787 \\
Group x Task type & $-0.08(0.07)$ & -1.11 & 0.268 \\
\hline
\end{tabular}


The contribution of model-based vs. model-free learning may be hypothesized to differ based on the state of illness. At Time 1, patients were generally undernourished (with potential sequelae for neurocognitive functioning) and had higher psychological symptom burden (e.g., depression and anxiety, see Table 1). Therefore, we tested participants before (Time 1) and after (Time 2) weight restoration treatment. Although there appeared to be a tendency toward more modelbased behavior at Time 2 in both groups, this main effect was not significant $(p=0.15)$ and there was no interaction between group and Session (Time 1 vs. Time 2) on model-based learning (Est: 0.02, SE =0.08, $z=0.27, p=0.79$, Fig. 3B).

A

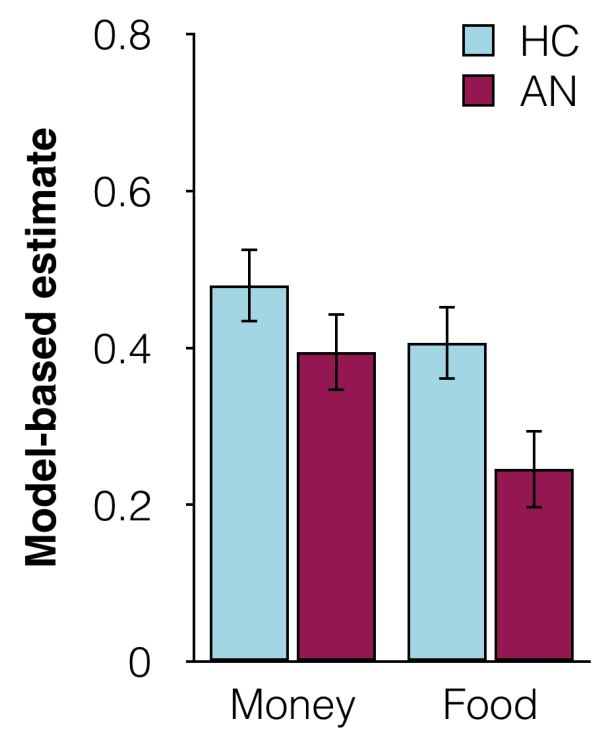

Outcome type
B

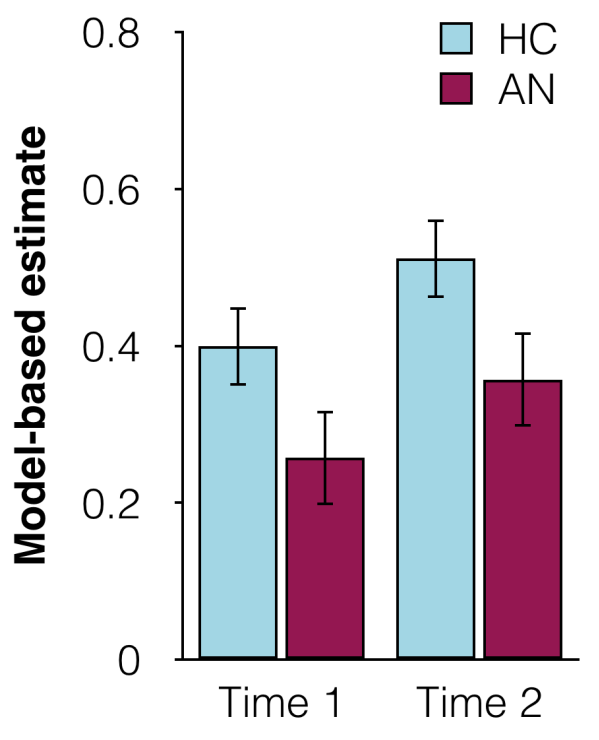

Session

Figure 3: A) Model-based contributions to learning for the monetary and food tasks across session (Time 1 and Time 2). B) Model-based contributions to learning at Time 1 and Time 2 across task type (monetary and food task).

\section{Post-Test Assessment of Task Transition Structure}

$\mathrm{HC}$ and $\mathrm{AN}$ did not differ significantly in their recall of the transition structure for the monetary or food outcomes task at Time 1 (Money: $X^{2}(1, N=87)=0.274, p=0.60$; Food: $X^{2}(1, N=84)=$ 0.925, $p=0.34$ ) or Time 2 (Money: $\chi^{2}(1, N=52)=0.006, p=0.94$; Food: $X^{2}(1, N=52)=0.650$, $p=0.42)$. $\mathrm{HC}$ and AN also did not differ significantly on the average discrepancy between their estimates of the transition probabilities and the actual probabilities at Time 1 (Money: $t(82)=-$ 0.91, $\mathrm{p}=0.37$; Food: $\mathrm{t}(82)=-0.59, \mathrm{p}=0.56$ ) or Time 2 (Money: $\mathrm{t}(51)=-1.73, \mathrm{p}=0.09$; Food: $t(51)=-1.34, p=0.18)$. 
medRxiv preprint doi: https://doi.org/10.1101/19002089; this version posted July 14, 2019. The copyright holder for this preprint (which was not certified by peer review) is the author/funder, who has granted medRxiv a license to display the preprint in perpetuity. It is made available under a CC-BY-ND 4.0 International license .

\section{Correlations with clinical variables}

Model-based behavior was not significantly associated with BMI (over and above the group difference) or duration of illness in the patient group (BMI: Est: 0.003, SE =0.03, z =0.09, p = 0.93; Duration: Est: 0.05, SE $=0.07, z=0.80, p=0.42$ ). In AN at Time 1, higher scores on the YBC-EDS were associated with less model-based learning for food outcomes relative to monetary outcomes (Est: 0.09, SE $=0.05, z=1.95, p=0.051$ ), a trend mainly driven by (and significant for) the Preoccupations subscale (Est: 0.13, SE $=0.04, z=3.07, p=0.002$ ) rather than the Rituals subscale (Est: 0.04, SE $=0.05, z=0.77, p=0.44$ ). (Data were not collected from $\mathrm{HC}$, for whom scores would be expected to be zero, or from AN after weight restoration.)

\section{AN subtypes}

Individuals with AN can be classified as either restricting (AN-R) or binge eating/purging (ANBP) subtype and the current sample was split approximately equally between subtypes (19 ANR, 22 AN-BP). Exploratory analyses suggested that the impairment in model-based learning was largely driven by individuals with AN meeting criteria for binge-eating/purging, rather than restricting subtype (see supplementary material and supplementary Fig. S1).

\section{DISCUSSION}

This study addressed three questions about the intersection of computational neuroscience and psychiatry by examining goal-directed and habitual learning mechanisms in AN. We tested whether AN, which appears at once excessively goal-directed and habitual, is characterized by enhanced or diminished model-based behavior. We further examined model-based versus model-free learning in a food-specific context as well as a monetary context, to test the domainspecificity of any differences, and before and after weight restoration, to test whether impairments were present only during acute illness or were instead a more stable characteristic of patients with AN. Individuals with AN showed less model-based learning than HC, and groups did not differ in model-free learning. This group difference was present when playing for both food and monetary outcomes and persisted after successful weight-restoration treatment.

How does the extreme, yet inflexible, "self-control" that characterizes AN relate to model-based learning?

AN poses a fascinating conceptual challenge for the classic psychological dichotomy between goal-directed, controlled behavior and inflexible, habitual responses. Selection of a low-fat, low 
calorie diet with limited variety is a stereotyped feature of illness in AN (Mayer, Schebendach, Bodell, Shingleton, \& Walsh, 2012; Schebendach et al., 2008; Sysko, Walsh, Schebendach, \& Wilson, 2005). Yet nearly half of patients also engage in eating that is accompanied by a sense of loss of control (binge eating). The coexistence of these behaviors, as well as other indicators that behavior is actually quite inflexible in AN, makes this illness particularly intriguing as an opportunity to better understand the relative contributions of goal-directed and habitual behavior. Maladaptive behaviors in AN are commonly understood to reflect heightened selfcontrol, which might be expected to relate to enhanced dominance of goal-directed (or modelbased) behavior. Yet these same behaviors are also rigid and difficult to change, which might suggest the opposite result: relatively weakened model-based control. This study allowed us to test existing hypotheses that impairments in goal-directed, or model-based, behavior are a transdiagnostic mechanism underlying compulsive psychopathology (Gillan et al., 2016; Voon et al., 2015).

Our results suggest that, compared to $\mathrm{HC}, \mathrm{AN}$ rely significantly less on the model-based approach, similar to individuals with other disorders involving compulsion such as OCD or drug abuse (Gillan et al., 2016; Voon et al., 2015). The pathology of AN involves complex, multi-step phenomena to avoid food intake. The findings in this study suggest that these computational mechanisms may be relevant even to producing behaviors, like pathological food avoidance, that extend beyond the traditional notion from animal behavioral psychology of habits as simple stimulus-response motor programs. Indeed, a recent study in a large general population sample found that model-based behavior in the Two-Step task, used herein, correlated with a set of psychiatric symptoms that included not just simple compulsive actions (such as repetitive checking or morning drinking) that extend easily from a basic notion of habits but also broader, more cognitive symptoms such as intrusive thoughts (Gillan et al., 2016). In contrast, this study found no significant difference between $\mathrm{AN}$ and $\mathrm{HC}$ in the model-free approach in the task, and groups also differed significantly in a composite index of relative reliance on the two systems, supporting the specificity of the effect. That said, as with previous studies using this task (Gillan et al., 2016), we focused our hypotheses and analyses on the modulation of model-based behavior, as this has proven to be the measure from this task that has most reliably tracked manipulations or individual differences likely to be relevant to the goal-habit balance (Otto, Raio, et al., 2013; Otto, Skatova, Madlon-Kay, \& Daw, 2015). 
medRxiv preprint doi: https://doi.org/10.1101/19002089; this version posted July 14, 2019. The copyright holder for this preprint (which was not certified by peer review) is the author/funder, who has granted medRxiv a license to display the preprint in perpetuity. It is made available under a CC-BY-ND 4.0 International license .

Does specific psychopathology reflect a domain-general failure of model-based learning? Our data indicate that the deficit in model-based learning in AN was not significantly remediated by using food outcomes. Rather, it was consistent across both domain-general (money) and illness-specific (food) outcomes, with no significant task differences in the group effect. This finding cuts against one potential explanation for the current results on the money task and other similar results showing reduced model-based learning for money in psychiatric populations (Voon et al., 2015): that generic monetary outcomes are less motivating in psychiatric populations than they are for $\mathrm{HC}$ participants. Interestingly, it has recently been shown that incentives can reliably boost model-based performance-even in the more severe end of the spectrum for a range of psychopathology constructs (Patzelt, Kool, Millner, \& Gershman, 2019). By using an incentive-compatible food outcome (success on the Two-Step task led to actual snack choices after the task), the present study included a condition in which motivation would be expected to be more salient for individuals with AN than for HC. Yet, even in the food context, patients with AN showed less model-based behavior than HC. Of course, the failure to detect a Group-by-Task interaction is a negative result, and as with any such result, the possibility remains that there does exist some interaction smaller than our study was powered to detect. However, this is mitigated by a positive result: that AN were significantly impaired at model-based learning, relative to $\mathrm{HC}$, even in the food task considered alone (Est=0.17, SE=0.067, z=2.6, $\mathrm{p}=0.01$ ).

Exploratory analyses of the relationship between symptom severity and task performance in AN did suggest one result that was selective for the food task: higher scores on the YBC-EDS, especially the Preoccupation subscale, were associated with less model-based learning for food outcomes relative to monetary outcomes. Such a graded deficit seems plausible, and its specificity to food intriguing, but it is of note that the direction of the effect (worse learning with food outcomes) is opposite that predicted by a motivational account. Also, given the exploratory nature of the analysis and the smaller number of data points underlying it, there is a danger of false positives and replication will be required to confirm this finding.

\section{Are model-based deficits secondary to psychopathology, or potentially primary?}

The idea that compulsive psychopathology might relate to impaired model-based learning is appealing in part because it hints at a causal mechanism by which pathological habits might emerge. Of course we are not in a position to address causality, nor even whether the cognitive 
medRxiv preprint doi: https://doi.org/10.1101/19002089; this version posted July 14, 2019. The copyright holder for this preprint (which was not certified by peer review) is the author/funder, who has granted medRxiv a license to display the preprint in perpetuity. It is made available under a CC-BY-ND 4.0 International license .

deficits precede the symptoms. However, we were able to address whether the cognitive differences between AN and $\mathrm{HC}$ persisted after acute weight restoration. That they did indicates they were not due to starvation alone. Prior research has shown that while psychological measures improve with weight restoration, eating behavior-namely, the pursuit of low-fat lowcalorie diets-does not improve substantially with weight restoration (Mayer et al., 2012; Sysko et al., 2005). Additionally, in a previous study we found that deficits in feedback-based learning remained after weight restoration (Foerde \& Steinglass, 2017). The effect on model-based learning here shows a similar persistence, consistent with model-based deficits as a relatively stable characteristic in AN. This result also parallels a recent report, using the same task, that cognitive behavioral therapy for OCD also does not improve goal-directed deficits in that population (Wheaton et al., 2018). In the current dataset, the absence of an effect of weight restoration is a negative result and subject to similar interpretational caveats as the money vs. food contrast. However, the confidence interval on the effect suggests that any undetected effect of weight restoration on model-based behavior is likely to be quite small relative to the overall deficit.

\section{Conclusion}

Previous work has shown deficits in responding to reward (DeGuzman, Shott, Yang, Riederer, \& Frank, 2017; Frank, Shott, Hagman, \& Mittal, 2013; O'Hara, Campbell, \& Schmidt, 2015) and learning from feedback in AN (Foerde \& Steinglass, 2017; Lawrence et al., 2003; Shott et al., 2012). The present results suggest that a more fine-grained parsing of this deficit is necessary. Basic habitual learning mechanisms may be intact, whereas flexible responses to changing contingencies and the ability to integrate a model of the environment into choices are impaired. Individuals with AN understood the structure of the task as well as did $\mathrm{HC}$, as both groups were able to report verbally on the rules of transition in the task. Yet, individuals with AN were less able to successfully use this information in their decision-making during the task. These findings are consistent with the habit-centered model of AN (Walsh, 2013), which argues that, once established, patterns of maladaptive eating in AN are no longer goal-directed. Relatedly, maladaptive food choice is mediated in AN by dorsal striatum (Foerde et al., 2015).

Nonetheless, a paradox remains in that individuals with AN are characterized by less modelbased behavior but also more patient delay discounting in inter-temporal choices (Decker et al., 2015; Steinglass et al., 2012; Steinglass et al., 2017). Generally, decreased model-based 
behavior would be expected to be associated with increased delay discounting: both are broadly associated with impulsivity, both are related to measures of executive functioning (Otto et al., 2015; Shamosh et al., 2008), and both are enhanced by increasing dopamine levels in patients with Parkinson's disease (Foerde et al., 2016; Sharp, Foerde, Daw, \& Shohamy, 2016). Also, a recent study found that they were related across individuals (Hunter, Bornstein, \& Hartley, 2018). One potential resolution of the paradox could lie with further consideration of subtypes of AN. The present study found that the deficit in model-based learning was primarily present in the AN-BP rather than the AN-R subtype (a pattern also found in a previous study, (Foerde \& Steinglass, 2017)). In contrast, decreased delay discounting has primarily been seen in the AN$\mathrm{R}$ rather than the AN-BP subtype (Decker et al., 2015; Steinglass et al., 2012). Further explication of these patterns will rely on larger samples suited to parse the contributions of subtypes and computational neuroscience and psychiatry approaches may be fruitful in understanding the distinct manifestations of psychopathology within complex illnesses such as AN.

The divergence between goal-directed and habitual behavior in AN could have implications for how illness develops and how it becomes resistant to change. It is particularly important for an illness that often develops in adolescence, a time during which model-free learning reigns and model-based behavior only begins to emerge (Decker et al., 2016). The slower emergence of model-based behavior across development suggests one mechanism that may nudge dieting behavior down the habit (model-free) path, and may be one contributing factor to how this eating behavior becomes so entrenched. More generally, these results also speak to the promise of the goal-directed vs habitual dichotomy as a trans-diagnostic mechanism, associated with compulsive symptomatology across disorders: the decision-making deficit here was domain-general, not food-specific, and apparently not secondary to starvation. Finally, they speak as well to the architecture of decision making in the healthy brain: they suggest that the sorts of behaviors emitted in the absence of control go well beyond simple stimulus-response habits, speaking to the inadequacy of current psychological and computational conceptions of automatic behavior.

In summary, we found that model-based, and not model-free, behavior was impaired among individuals with $\mathrm{AN}$ relative to $\mathrm{HC}$. The deficit was not remediated by using real food as the 
medRxiv preprint doi: https://doi.org/10.1101/19002089; this version posted July 14, 2019. The copyright holder for this preprint (which was not certified by peer review) is the author/funder, who has granted medRxiv a license to display the preprint in perpetuity.

It is made available under a CC-BY-ND 4.0 International license.

outcomes of choices to enhance motivational salience nor by weight restoration and associated improvement in psychological symptoms. 


\section{MATERIALS AND METHODS}

\section{Participants}

Participants were 41 women with AN and 53 healthy comparison women $(\mathrm{HC})$. Individuals were eligible if they were between the ages of 16 and 46 years (Table 1), with an estimated IQ $>80$ (measured by Wechsler Abbreviated Scale of Intelligence, WASI-II, (Wechsler, 1999)). Eligible patients met DSM-5 (American Psychiatric Association, 2013) criteria for AN-restricting (AN-R, $\mathrm{n}=19$ ) or binge eating/purging (AN-BP, $\mathrm{n}=22$ ) subtype-and were receiving inpatient treatment at the New York State Psychiatric Institute (NYSPI) specialized Eating Disorders Unit. Patients with AN were not eligible if they had a history of a psychotic disorder, were at imminent risk of suicide, or met criteria for substance use disorder. Anxiety and depressive disorders were not exclusionary, as these commonly co-occur with AN (Hudson, Hiripi, Pope, \& Kessler, 2007). Three individuals with AN were taking antidepressant medications (SSRIs). HC were recruited through the community and were compensated $\$ 50$ for their time. $\mathrm{HC}$ were group-matched for age and ethnicity and were included if they had no current or past psychiatric illness, including any history of an eating disorder, and had a body mass index (BMI) in the normal range (18-25 $\mathrm{kg} / \mathrm{m}^{2}$ ). The HC group included 19 individuals who endorsed a history of dieting behavior. This study was approved by the NYSPI Institutional Review Board; after complete description of the study to the participants, adult participants provided written informed consent and adolescents provided written assent with parental consent.

\section{Procedure}

Psychiatric diagnoses were established using the Semi Structured Interview for DSM-IV (SCID; (First, Spitzer, Gibbon, \& Williams, 2002) and the Eating Disorders Assessment for DSM5 (EDA-5, (Sysko et al., 2012)). Height and weight were obtained on a beam balance scale (Detecto, Webb, MO). Estimated IQ was assessed with the WASI-II (Wechsler, 1999). Severity of eating disorder psychopathology was measured by the Eating Disorder Examination Questionnaire (EDE-Q; (Fairburn, 2008; Fairburn \& Beglin, 1994)), a 36-item self-report assessment of eating disorder symptoms which has established community norms for adolescents and adults. The four symptom subscales (Restraint, Eating Concern, Shape Concern, and Weight Concern) are scored on a scale of 0-6 and averaged to obtain a "global" score. In addition, participants with AN completed the Yale-Brown-Cornell Eating Disorder Scale (YBC-EDS; (Mazure, Halmi, Sunday, Romano, \& Einhorn, 1994)), an interview measure of eating disorder symptoms with separate subscales related to Preoccupations and Rituals. Each 
medRxiv preprint doi: https://doi.org/10.1101/19002089; this version posted July 14, 2019. The copyright holder for this preprint (which was not certified by peer review) is the author/funder, who has granted medRxiv a license to display the preprint in perpetuity. It is made available under a CC-BY-ND 4.0 International license .

subscale is scored on a scale from 0-16 and the subscales are summed to obtain the total score (ranging from 0-32). Higher scores indicate greater symptom severity on each measure.

Participants were assessed at two points: Individuals with AN were tested within 1 week of hospital admission (Time 1) and again after inpatient weight restoration treatment to at least 90\% ideal body weight (Metropolitan Life Insurance, 1959), corresponding to a body mass index (BMI) of approximately $19.5-20.0 \mathrm{~kg} / \mathrm{m}^{2}$ (Time 2). HC individuals were tested twice at an interval group matched to $A N\left(M_{H C}=51+/-23\right.$ days, $M_{A N}=59+/-22$ days, $\left.t(45)=1.17, p=0.25\right)$. Of 41 AN participants, 18 completed both time points, 16 completed only Time 1, and seven completed only Time 2; of $53 \mathrm{HC}$ participants, 29 completed both time points and 24 completed only Time 1. For one AN participant, data from the food outcome task at Time 2 was lost due to computer malfunction.

\section{Two-Step Decision Task}

Each participant completed two versions of the Two-Step Decision Task (Daw et al., 2011; Decker et al., 2016; Sharp et al., 2016) -one that involved playing for money and one that involved playing for a food snack to be consumed after the task (order counterbalanced across participants). The tasks were structurally identical but included distinct cover stories and task environments that matched the outcomes used (see Fig. 1AB). For both tasks each trial proceeded in two stages (Fig. 1C). In the first stage (Stage 1), participants chose between two spaceships (or cafés), revealing a second-stage (Stage 2) choice between two aliens (or food trays). Each second-stage alien (or food tray) had a slowly changing chance of delivering space treasure (or a food token) vs. nothing, necessitating continuous learning by trial and error. The four Stage 2 options were determined by independently drifting Gaussian random walks with a standard deviation $=0.025$ and bounded by 0.25 and 0.75 probability of reward, such that the reward probability associated with each Stage 2 option changed slowly from trial to trial (Fig. 1D). The response window at each stage was three seconds. Participants completed 200 trials of each task.

A key design feature of the task was the probabilistic association between first- and secondstage choices: Choosing the blue spaceship (or blue café) lead to the purple planet (or green kitchen) $70 \%$ of the time-a common transition, and the red planet (yellow kitchen) $30 \%$ of the time-a rare transition. The contingencies were reversed for the green spaceship (pink café). 
medRxiv preprint doi: https://doi.org/10.1101/19002089; this version posted July 14, 2019. The copyright holder for this preprint (which was not certified by peer review) is the author/funder, who has granted medRxiv a license to display the preprint in perpetuity. It is made available under a CC-BY-ND 4.0 International license .

The transition structure between stages allows dissociation of model-free vs. model-based learning strategies: Model-free learning is ignorant of transition structure and favors repeating a first-step choice that ultimately results in reward, even if it does so via a low probability transition. By contrast, model-based learning is sensitive to the transition contingencies and uses them to infer the first-stage choice most likely to lead to the preferred second-stage environment.

In the monetary version of the task, each piece of space treasure collected was worth $\$ 0.10$ and the total earned was paid out in cash at the end of the experiment. In the food version of the task, the accrued tokens bought access to a selection of foods from which to choose a snack item. Prior to completing the task, participants were given a "menu" (supplementary Fig. S2) with pictures of 15 food items and were asked to rank them in order of preference, but were not told that the ratings were related to later snack options. An increasing number of earned food tokens granted access to an increasing number of preferred food items (e.g., 92 tokens provided access to items ranked 9-15, 114 tokens or more provided access to all items, see supplementary Table S1).

A subset of participants ( $H C: n=9, A N: n=18$ ) completed a different version of the food decision task (the monetary task was the same for all participants). In this version, rather than receiving a food token vs. nothing as the second-stage outcome, participants saw a picture of a preferred food item vs. a non-preferred food item. The specific food items were individually determined per participant: prior to the decision task participants completed a rating task in which 9 food items were rated on a scale from 1-9 (1= highly preferred). Participants were not instructed that their ratings would relate to their later snack options. The food image participants received on most trials determined which snack they would receive after the task. In this task, participants had 2 seconds to make choices in both stages. Results were qualitatively similar for both food tasks, and they were therefore combined in all analysis below.

After completing the Two-step tasks, participants' knowledge of the transition structure between Stage 1 and Stage 2 (e.g., If you picked the blue spaceship, which planet would you most likely land on?) and their estimates of the transition probabilities were assessed (e.g., If you picked the blue spaceship, how likely would you be to see the purple planet?). Responses were not 
collected from $3 \mathrm{HC}$ for the monetary task at Time 1 and from $1 \mathrm{AN}$ on both the monetary and food tasks at Time 2.

\section{Data analysis}

Demographic and clinical variables were compared using independent t-tests. Measures of psychopathology at Time 1 and Time 2 were compared within AN using paired t-tests.

\section{Assessment of Model-based and Model-free learning (Computational Model)}

In order to capture the influence of incremental learning across many trials, we fit subjects' choices using a reinforcement learning model in which choices are modeled as arising due to the weighted combination of model-free and model-based reinforcement learning. The model is equivalent to the one used by Gillan et al. (Gillan et al., 2016) and Otto et al. (Otto, Raio, et al., 2013), except that following Sharp et al. (Sharp et al., 2016) we have eliminated one free parameter (by setting $\beta^{M F 0}$ in the Glllan model to 0 , or equivalently $\lambda$ in the Otto model to 1 ). It reflects a simplification and a change of variables over the model from Daw et al. (Daw et al., 2011).

On each trial, $t$, participants make a Stage 1 choice $c_{1, t}$, leading to a transition to a Stage 2 state $s_{t}$ where another choice, $c_{2, t}$ is made, followed by reward $r_{t}$. At Stage 2 , it is assumed that participants learn a value function over states and choices, $Q^{\text {stage2 }}(s, c)$, whose value for the chosen action is updated based on the reward received at each trial according to a delta rule, $Q_{t+1}^{\text {stage } 2}\left(s_{t}, c_{2, t}\right)=(1-\alpha) Q_{t}^{\text {stage } 2}\left(s_{t}, c_{2, t}\right)+r_{t}$. Here, $\alpha$ is a free learning rate parameter. (In this, and analogous update equations, a factor of $\alpha$ is omitted from the last term of the update, equivalent to rescaling the rewards and $Q$ s by $\frac{1}{\alpha}$ and the corresponding weighting parameters $\beta$ by $\alpha$ (Otto, Raio, et al., 2013)). The probability of a particular Stage 2 choice is modeled as governed by these values according to a logistic softmax, with free inverse temperature parameter $\beta^{\text {stage } 2}: P\left(c_{2, t}=c\right) \propto \exp \left(\beta^{\text {stage } 2} Q_{t}^{\text {stage } 2}\left(s_{t}, c\right)\right)$, normalized over both options $c$.

Stage 1 choices are modeled as determined by the weighted combination of both model-free and model-based value predictions about the ultimate, Stage 2 value of each Stage 1 choice. Model-based values $Q^{M B}$ are given by the learned values of the corresponding Stage 2 state, 
maximized over the two actions: $Q^{M B}(c)=\max _{c 2}\left(Q_{t}^{\text {stage } 2}\left(s, c_{2}\right)\right)$, where $s$ is the Stage 2 state predominantly produced by Stage 1 choice $c$. Model-free values are learned by TD(1), where $Q_{t+1}^{M F}\left(c_{1}, t\right)=(1-\alpha) Q_{t}^{M F}+r_{t}$. The Stage 1 choice probabilities are given by a logistic softmax, with a contribution from each value estimate weighted by its own free inverse temperature parameter: $P\left(c_{1, t}=c\right) \propto \exp \left(\beta^{M B} Q_{t}^{M B}(c)+\beta^{M F} Q_{t}^{M F}(c)+\beta^{s t i c k} I\left(c=c_{1, t-1}\right)\right.$. Here, $I\left(c=c_{1, t-1}\right)$ is a binary indicator of whether a choice repeats the previous trial's choice, so the weight $\beta^{\text {stick }}$ measures the general tendency to perseverate or switch regardless of feedback.

At the end of each trial, all value estimates $Q$ for unchosen actions and unvisited states are decayed by multiplying by $(1-\alpha)$.

The model has a total of five free parameters: four weights $\beta\left(\beta^{\text {stage } 2}, \beta^{M B}, \beta^{M F}, \beta^{\text {stick }}\right.$ and a learning rate $\alpha$. Our main measures of interest are $\beta^{M B}$ and $\beta^{M F}$, measuring the contribution of model-based and model-free learning.

The free parameters of the model were estimated by maximizing the likelihood of each participant's sequence of choices, using a distinct set of parameters for each game (i.e., each combination of participant, session, and task type: up to four games per participant, two task types at two timepoints). These were estimated jointly with group-level distributions over the entire population using an Expectation Maximization procedure (Huys et al., 2011) implemented in the Julia language (Bezanson, Karpinski, Shah, \& Edelman, 2012). The per-game modelbased and model-free weightings $\beta^{M B}$ and $\beta^{M F}$, indicating the strength of each type of learning, were extracted for further analysis. (We also computed a standard measure of their relative fractional reliance, $w=\frac{\beta^{M B}}{\beta^{M B}+\beta^{M F}}$; Daw et al, 2011.) These estimates were used as dependent variables in a series of regression analyses with group as the main explanatory variable of interest. All analyses controlled for task type, session, IQ, and age as additional independent variables. In followup analyses, we included interactions of group by session or task, and measures of disease severity (BMI, duration illness, and YBC-EDS); all covariates were zscored. The regressions were conducted using mixed-effects logistic regression, and estimated using Julia's MixedModels package. All within-subject parameters (e.g. task and session) were taken as random effects per participant, so as the to capture the repeated-measure structure of 
medRxiv preprint doi: https://doi.org/10.1101/19002089; this version posted July 14, 2019. The copyright holder for this preprint (which was not certified by peer review) is the author/funder, who has granted medRxiv a license to display the preprint in perpetuity. It is made available under a CC-BY-ND 4.0 International license .

the data (e.g., tasks repeated at two timepoints) and also the imbalanced data (e.g., not all subjects completed both timepoints). 


\section{REFERENCES}

American Psychiatric Association: DSM-5 task force. (2013). Diagnostic and Statistical Manual of Mental Disorders: DSM-5. Arlington,VA: American Psychiatric Association.

Beck, A. T., \& Steer, R. A. (1993). Depression Inventory Manual. San Antonio, TX: Psychological Corporation, Harcourt, Brace.

Bezanson, J., Karpinski, S., Shah, V. B., \& Edelman, A. (2012). Julia: A fast dynamic language for technical computing. . arXiv preprint arXiv:1209.5145.

Bruch, H. (1979). Golden Cage: The Enigma of Anorexia Nervosa: Harvard University Press

Coutureau, E., \& Killcross, S. (2003). Inactivation of the infralimbic prefrontal cortex reinstates goal-directed responding in overtrained rats. Behav Brain Res, 146(1-2), 167-174.

Retrieved from

http://www.ncbi.nlm.nih.gov/entrez/query.fcgi?cmd=Retrieve\&db=PubMed\&dopt=Citation \&list_uids $=14643469$

Daw, N. D., Gershman, S. J., Seymour, B., Dayan, P., \& Dolan, R. J. (2011). Model-based influences on humans' choices and striatal prediction errors. Neuron, 69(6), 1204-1215. Retrieved from http://www.ncbi.nlm.nih.gov/pubmed/21435563. doi:10.1016/j.neuron.2011.02.027

Daw, N. D., Niv, Y., \& Dayan, P. (2005). Uncertainty-based competition between prefrontal and dorsolateral striatal systems for behavioral control. Nature Neuroscience, 8(12), 17041711.

Decker, J. H., Figner, B., \& Steinglass, J. E. (2015). On Weight and Waiting: Delay Discounting in Anorexia Nervosa Pretreatment and Posttreatment. Biol Psychiatry, 78(9), 606-614. Retrieved from https://www.ncbi.nlm.nih.gov/pubmed/25641636. doi:10.1016/j.biopsych.2014.12.016

Decker, J. H., Otto, A. R., Daw, N. D., \& Hartley, C. A. (2016). From Creatures of Habit to GoalDirected Learners: Tracking the Developmental Emergence of Model-Based Reinforcement Learning. Psychol Sci, 27(6), 848-858. Retrieved from https://www.ncbi.nlm.nih.gov/pubmed/27084852. doi:10.1177/0956797616639301

DeGuzman, M., Shott, M. E., Yang, T. T., Riederer, J., \& Frank, G. K. W. (2017). Association of Elevated Reward Prediction Error Response With Weight Gain in Adolescent Anorexia Nervosa. Am J Psychiatry, 174(6), 557-565. Retrieved from https://www.ncbi.nlm.nih.gov/pubmed/28231717. doi:10.1176/appi.ajp.2016.16060671

Dickinson, A., \& Balleine, B. (2002). The role of learning in the operation of motivational systems. In H. Pashler \& R. Gallistel (Eds.), Steven's handbook of experimental psychology (3rd ed.), Vol. 3: Learning, motivation, and emotion. (pp. 497-533). New York, NY, US: John Wiley \& Sons, Inc.

Everitt, B. J., \& Robbins, T. W. (2016). Drug Addiction: Updating Actions to Habits to Compulsions Ten Years On. Annu Rev Psychol, 67, 23-50. Retrieved from 
medRxiv preprint doi: https://doi.org/10.1101/19002089; this version posted July 14, 2019. The copyright holder for this preprint (which was not certified by peer review) is the author/funder, who has granted medRxiv a license to display the preprint in perpetuity. It is made available under a CC-BY-ND 4.0 International license .

https://www.ncbi.nlm.nih.gov/pubmed/26253543. doi:10.1146/annurev-psych-122414033457

Fairburn, C. G. (2008). Cognitive Behavior Therapy and Eating Disorders. New York: Guilford Press.

Fairburn, C. G., \& Beglin, S. J. (1994). Assessment of eating disorders: interview or self-report questionnaire? Int $J$ Eat Disord, 16(4), 363-370. Retrieved from https://www.ncbi.nlm.nih.gov/pubmed/7866415.

First, M. B., Spitzer, R. L., Gibbon, M., \& Williams, J. B. (2002). Structured Clinical Interview for DSM-IV-TR Axis I Disorders-Patient Edition (SCID-I/P). New York, NY: Biometrics Research Department, New York State Psychiatric Institute.

Foerde, K., Figner, B., Doll, B. B., Woyke, I. C., Braun, E. K., Weber, E. U., \& Shohamy, D. (2016). Dopamine Modulation of Intertemporal Decision-making: Evidence from Parkinson Disease. J Cogn Neurosci, 28(5), 657-667. Retrieved from http://www.ncbi.nlm.nih.gov/pubmed/26836514. doi:10.1162/jocn_a_00929

Foerde, K., \& Steinglass, J. E. (2017). Decreased feedback learning in anorexia nervosa persists after weight restoration. Int J Eat Disord, 50(4), 415-423. Retrieved from https://www.ncbi.nlm.nih.gov/pubmed/28393399. doi:10.1002/eat.22709

Foerde, K., Steinglass, J. E., Shohamy, D., \& Walsh, B. T. (2015). Neural mechanisms supporting maladaptive food choices in anorexia nervosa. Nat Neurosci, 18(11), 15711573. Retrieved from http://www.ncbi.nlm.nih.gov/pubmed/26457555.

doi:10.1038/nn.4136

Frank, G. K., Shott, M. E., Hagman, J. O., \& Mittal, V. A. (2013). Alterations in brain structures related to taste reward circuitry in ill and recovered anorexia nervosa and in bulimia nervosa. Am J Psychiatry, 170(10), 1152-1160. Retrieved from http://www.ncbi.nlm.nih.gov/pubmed/23680873. doi:10.1176/appi.ajp.2013.12101294

Gillan, C. M., Apergis-Schoute, A. M., Morein-Zamir, S., Urcelay, G. P., Sule, A., Fineberg, N. A., ... Robbins, T. W. (2015). Functional neuroimaging of avoidance habits in obsessive-compulsive disorder. Am J Psychiatry, 172(3), 284-293. Retrieved from https://www.ncbi.nlm.nih.gov/pubmed/25526600. doi:10.1176/appi.ajp.2014.14040525

Gillan, C. M., \& Robbins, T. W. (2014). Goal-directed learning and obsessive-compulsive disorder. Philos Trans $R$ Soc Lond B Biol Sci, 369(1655). Retrieved from https://www.ncbi.nlm.nih.gov/pubmed/25267818. doi:10.1098/rstb.2013.0475

Gillan, C. M., Robbins, T. W., Sahakian, B. J., van den Heuvel, O. A., \& van Wingen, G. (2016). The role of habit in compulsivity. Eur Neuropsychopharmacol, 26(5), 828-840. Retrieved from http://www.ncbi.nlm.nih.gov/pubmed/26774661. doi:10.1016/j.euroneuro.2015.12.033

Glascher, J., Daw, N., Dayan, P., \& O'Doherty, J. P. (2010). States versus rewards: dissociable neural prediction error signals underlying model-based and model-free reinforcement learning. Neuron, 66(4), 585-595. Retrieved from 
medRxiv preprint doi: https://doi.org/10.1101/19002089; this version posted July 14, 2019. The copyright holder for this preprint (which was not certified by peer review) is the author/funder, who has granted medRxiv a license to display the preprint in perpetuity. It is made available under a CC-BY-ND 4.0 International license .

http://www.ncbi.nlm.nih.gov/entrez/query.fcgi?cmd=Retrieve\&db=PubMed\&dopt=Citation \&list uids=20510862. doi:S0896-6273(10)00287-4 [pii]10.1016/j.neuron.2010.04.016

Graybiel, A. M. (2008). Habits, rituals, and the evaluative brain. Annu Rev Neurosci, 31, 359387. Retrieved from http://www.ncbi.nlm.nih.gov/entrez/query.fcgi?cmd=Retrieve\&db=PubMed\&dopt=Citation \&list uids=18558860. doi:10.1146/annurev.neuro.29.051605.112851

Hudson, J. I., Hiripi, E., Pope, H. G., Jr., \& Kessler, R. C. (2007). The prevalence and correlates of eating disorders in the National Comorbidity Survey Replication. Biological Psychiatry, 61(3), 348-358. Retrieved from http://www.ncbi.nlm.nih.gov/entrez/query.fcgi?cmd=Retrieve\&db=PubMed\&dopt=Citation \&list uids $=16815322$

Hunter, L. E., Bornstein, A. M., \& Hartley, C. A. (2018). A common deliberative process underlies model-based planning and patient intertemporal choice. . bioRxiv, 499707.

Huys, Q. J., Cools, R., Golzer, M., Friedel, E., Heinz, A., Dolan, R. J., \& Dayan, P. (2011). Disentangling the roles of approach, activation and valence in instrumental and pavlovian responding. PLoS Comput Biol, 7(4), e1002028. Retrieved from https://www.ncbi.nlm.nih.gov/pubmed/21556131. doi:10.1371/journal.pcbi.1002028

Huys, Q. J., Maia, T. V., \& Frank, M. J. (2016). Computational psychiatry as a bridge from neuroscience to clinical applications. Nat Neurosci, 19(3), 404-413. Retrieved from https://www.ncbi.nlm.nih.gov/pubmed/26906507. doi:10.1038/nn.4238

James, W. (1890). The principles of psychology (Vol. 1). New York: Henry Holt.

Killcross, S., \& Coutureau, E. (2003). Coordination of actions and habits in the medial prefrontal cortex of rats. Cerebral Cortex 13(4), 400-408.

Lawrence, A. D., Dowson, J., Foxall, G. L., Summerfield, R., Robbins, T. W., \& Sahakian, B. J. (2003). Impaired visual discrimination learning in anorexia nervosa. Appetite, 40(1), 8589. Retrieved from http://www.ncbi.nlm.nih.gov/pubmed/12631509.

Lee, S. W., Shimojo, S., \& O'Doherty, J. P. (2014). Neural computations underlying arbitration between model-based and model-free learning. Neuron, 81(3), 687-699. Retrieved from https://www.ncbi.nlm.nih.gov/pubmed/24507199. doi:10.1016/j.neuron.2013.11.028

Mayer, L. E., Schebendach, J., Bodell, L. P., Shingleton, R. M., \& Walsh, B. T. (2012). Eating behavior in anorexia nervosa: before and after treatment. Int J Eat Disord, 45(2), 290293. Retrieved from

http://www.ncbi.nlm.nih.gov/entrez/query.fcgi?cmd=Retrieve\&db=PubMed\&dopt=Citation \&list uids=21495053. doi:10.1002/eat.20924

Mazure, C. M., Halmi, K. A., Sunday, S. R., Romano, S. J., \& Einhorn, A. M. (1994). The YaleBrown-Cornell Eating Disorder Scale: development, use, reliability and validity. $J$ Psychiatr Res, 28(5), 425-445. Retrieved from https://www.ncbi.nlm.nih.gov/pubmed/7897615. 
O'Hara, C. B., Campbell, I. C., \& Schmidt, U. (2015). A reward-centred model of anorexia nervosa: a focussed narrative review of the neurological and psychophysiological literature. Neurosci Biobehav Rev, 52, 131-152. Retrieved from https://www.ncbi.nlm.nih.gov/pubmed/25735957. doi:10.1016/j.neubiorev.2015.02.012

Otto, A. R., Gershman, S. J., Markman, A. B., \& Daw, N. D. (2013). The curse of planning: dissecting multiple reinforcement-learning systems by taxing the central executive. Psychol Sci, 24(5), 751-761. Retrieved from http://www.ncbi.nlm.nih.gov/pubmed/23558545. doi:10.1177/0956797612463080

Otto, A. R., Raio, C. M., Chiang, A., Phelps, E. A., \& Daw, N. D. (2013). Working-memory capacity protects model-based learning from stress. Proc Natl Acad Sci U S A, 110(52), 20941-20946. Retrieved from http://www.ncbi.nlm.nih.gov/pubmed/24324166. doi:10.1073/pnas.1312011110

Otto, A. R., Skatova, A., Madlon-Kay, S., \& Daw, N. D. (2015). Cognitive control predicts use of model-based reinforcement learning. J Cogn Neurosci, 27(2), 319-333. Retrieved from https://www.ncbi.nlm.nih.gov/pubmed/25170791. doi:10.1162/jocn_a_00709

Patzelt, E. H., Kool, W., Millner, A. J., \& Gershman, S. J. (2019). Incentives Boost Model-Based Control Across a Range of Severity on Several Psychiatric Constructs. Biol Psychiatry, 85(5), 425-433. Retrieved from https://www.ncbi.nlm.nih.gov/pubmed/30077331. doi:10.1016/j.biopsych.2018.06.018

Salkovskis, P. M. (1985). Obsessional-compulsive problems: a cognitive-behavioural analysis. Behav Res Ther, 23(5), 571-583. Retrieved from https://www.ncbi.nlm.nih.gov/pubmed/4051930.

Schebendach, J. E., Mayer, L. E., Devlin, M. J., Attia, E., Contento, I. R., Wolf, R. L., \& Walsh, B. T. (2008). Dietary energy density and diet variety as predictors of outcome in anorexia nervosa. Am J Clin Nutr, 87(4), 810-816. Retrieved from http://www.ncbi.nlm.nih.gov/entrez/query.fcgi?cmd=Retrieve\&db=PubMed\&dopt=Citation \&list uids $=18400701$

Shamosh, N. A., Deyoung, C. G., Green, A. E., Reis, D. L., Johnson, M. R., Conway, A. R., . . Gray, J. R. (2008). Individual differences in delay discounting: relation to intelligence, working memory, and anterior prefrontal cortex. Psychol Sci, 19(9), 904-911. Retrieved from https://www.ncbi.nlm.nih.gov/pubmed/18947356. doi:10.1111/j.14679280.2008.02175.x

Sharp, M., Foerde, K., Daw, N., \& Shohamy, D. (2016). Dopamine selectively remediates "model-based" reward learning: a computational approach. Brain, 139(2), 355-364.

Shott, M. E., Filoteo, J. V., Jappe, L. M., Pryor, T., Maddox, W. T., Rollin, M. D., . . Frank, G. K. (2012). Altered implicit category learning in anorexia nervosa. Neuropsychology, 26(2), 191-201. Retrieved from http://www.ncbi.nlm.nih.gov/pubmed/22201300.

doi:10.1037/a0026771 
medRxiv preprint doi: https://doi.org/10.1101/19002089; this version posted July 14, 2019. The copyright holder for this preprint (which was not certified by peer review) is the author/funder, who has granted medRxiv a license to display the preprint in perpetuity. It is made available under a CC-BY-ND 4.0 International license .

Spielberger, C. D., Gorsuch, R. L., \& Lushene, R. E. (1970). State-trait anxiety inventory. Palo Alto, CA: Consulting Psychologists Press.

Steinglass, J. E., Figner, B., Berkowitz, S., Simpson, H. B., Weber, E. U., \& Walsh, B. T. (2012). Increased Capacity to Delay Reward in Anorexia Nervosa. J Int Neuropsychol Soc, 1-8. Retrieved from http://www.ncbi.nlm.nih.gov/entrez/query.fcgi?cmd=Retrieve\&db=PubMed\&dopt=Citation \&list uids=22591835. . doi:S1355617712000446 [pii]10.1017/S1355617712000446

Steinglass, J. E., Lempert, K. M., Choo, T. H., Kimeldorf, M. B., Wall, M., Walsh, B. T., ... Simpson, H. B. (2017). Temporal discounting across three psychiatric disorders: Anorexia nervosa, obsessive compulsive disorder, and social anxiety disorder. Depress Anxiety, 34(5), 463-470. Retrieved from https://www.ncbi.nlm.nih.gov/pubmed/28009473. doi:10.1002/da.22586

Sysko, R., Roberto, C. A., Barnes, R. D., Grilo, C. M., Attia, E., \& Walsh, B. T. (2012). Testretest reliability of the proposed DSM-5 eating disorder diagnostic criteria. Psychiatry Res, 196(2-3), 302-308. Retrieved from http://www.ncbi.nlm.nih.gov/entrez/query.fcgi?cmd=Retrieve\&db=PubMed\&dopt=Citation \&list uids=22401974. . doi:S0165-1781(11)00805-5 [pii]10.1016/j.psychres.2011.12.021

Sysko, R., Walsh, B. T., Schebendach, J., \& Wilson, G. T. (2005). Eating behavior among women with anorexia nervosa. Am J Clin Nutr, 82(2), 296-301. Retrieved from http://www.ncbi.nlm.nih.gov/entrez/query.fcgi?cmd=Retrieve\&db=PubMed\&dopt=Citation \&list uids $=16087971$

Tiffany, S. T. (1990). A cognitive model of drug urges and drug-use behavior: role of automatic and nonautomatic processes. Psychol Rev, 97(2), 147-168. Retrieved from https://www.ncbi.nlm.nih.gov/pubmed/2186423.

Tricomi, E., Balleine, B. W., \& O'Doherty, J. P. (2009). A specific role for posterior dorsolateral striatum in human habit learning. Eur J Neurosci, 29(11), 2225-2232. Retrieved from http://www.ncbi.nlm.nih.gov/entrez/query.fcgi?cmd=Retrieve\&db=PubMed\&dopt=Citation \&list uids=19490086. doi:EJN6796 [pii]10.1111/j.1460-9568.2009.06796.x

Valentin, V. V., Dickinson, A., \& O'Doherty, J. P. (2007). Determining the neural substrates of goal-directed learning in the human brain. J Neurosci, 27(15), 4019-4026. Retrieved from http://www.ncbi.nlm.nih.gov/entrez/query.fcgi?cmd=Retrieve\&db=PubMed\&dopt=Citation \&list uids=17428979. doi:27/15/4019 [pii]10.1523/JNEUROSCI.0564-07.2007

Volkow, N. D., Wang, G. J., Fowler, J. S., Tomasi, D., Telang, F., \& Baler, R. (2010). Addiction: decreased reward sensitivity and increased expectation sensitivity conspire to overwhelm the brain's control circuit. Bioessays, 32(9), 748-755. Retrieved from https://www.ncbi.nlm.nih.gov/pubmed/20730946. doi:10.1002/bies.201000042

Voon, V., Derbyshire, K., Ruck, C., Irvine, M. A., Worbe, Y., Enander, J., . . Bullmore, E. T. (2015). Disorders of compulsivity: a common bias towards learning habits. Mol 
medRxiv preprint doi: https://doi.org/10.1101/19002089; this version posted July 14, 2019. The copyright holder for this preprint (which was not certified by peer review) is the author/funder, who has granted medRxiv a license to display the preprint in perpetuity.

It is made available under a CC-BY-ND 4.0 International license .

Psychiatry, 20(3), 345-352. Retrieved from http://www.ncbi.nlm.nih.gov/pubmed/24840709. doi:10.1038/mp.2014.44

Walsh, B. T. (2013). The enigmatic persistence of anorexia nervosa. Am J Psychiatry, 170(5), 477-484. Retrieved from http://www.ncbi.nlm.nih.gov/entrez/query.fcgi?cmd=Retrieve\&db=PubMed\&dopt=Citation \&list uids=23429750. doi:1654941 [pii]10.1176/appi.ajp.2012.12081074

Wechsler, D. (1999). Wechsler Abbreviated Scale of Intelligence manual. . San Antonio: The Psychological Corporation.

Weissengruber, S., Lee, S. W., O'Doherty, J. P., \& Ruff, C. C. (2019). Neurostimulation Reveals Context-Dependent Arbitration Between Model-Based and Model-Free Reinforcement Learning. Cereb Cortex. Retrieved from https://www.ncbi.nlm.nih.gov/pubmed/30888032. doi:10.1093/cercor/bhz019

Wheaton, M. G., Gillan, C. M., \& Simpson, H. B. (2018). Does cognitive-behavioral therapy affect goal-directed planning in obsessive-compulsive disorder? Psychiatry Res, 273, 94-99. Retrieved from https://www.ncbi.nlm.nih.gov/pubmed/30640057. doi:10.1016/j.psychres.2018.12.079

Yin, H. H., Knowlton, B. J., \& Balleine, B. W. (2004). Lesions of dorsolateral striatum preserve outcome expectancy but disrupt habit formation in instrumental learning. European Journal of Neuroscience, 19(1), 181-189.

Yin, H. H., Knowlton, B. J., \& Balleine, B. W. (2006). Inactivation of dorsolateral striatum enhances sensitivity to changes in the action-outcome contingency in instrumental conditioning. Behavioral Brain Research, 166(2), 189-196. 


\section{SUPPLEMENTARY INFORMATION FOR}

\section{Deficient goal-directed control in a population characterized by extreme goal pursuit.}

Karin Foerde, Nathaniel D. Daw, Teresa Rufin, B. Timothy Walsh, Daphna Shohamy, Joanna E. Steinglass 
medRxiv preprint doi: https://doi.org/10.1101/19002089; this version posted July 14, 2019. The copyright holder for this preprint (which was not certified by peer review) is the author/funder, who has granted medRxiv a license to display the preprint in perpetuity.

It is made available under a CC-BY-ND 4.0 International license .

\section{Model-based performance in $A N-R$ vs. AN-BP subtypes}

We further assessed model-based performance separately for ANs meeting criteria for restricting (AN-R) vs. binge-eating/purging (AN-BP) subtype. As seen in Figure S1, HC were most model-based, and AN-BP least model-based, with AN-R falling in between. The HC and AN-BP groups differed significantly from each other (Est: $0.21, S E=0.06, z=3.36, p=0.0008$, whereas AN-R did not differ significantly from AN-BP (Est: 0.12, SE =0.09, z = 1.33, p = 0.18) or HC (Est: -0.09 , SE $=0.08, z=-1.05, p=0.29$ ).

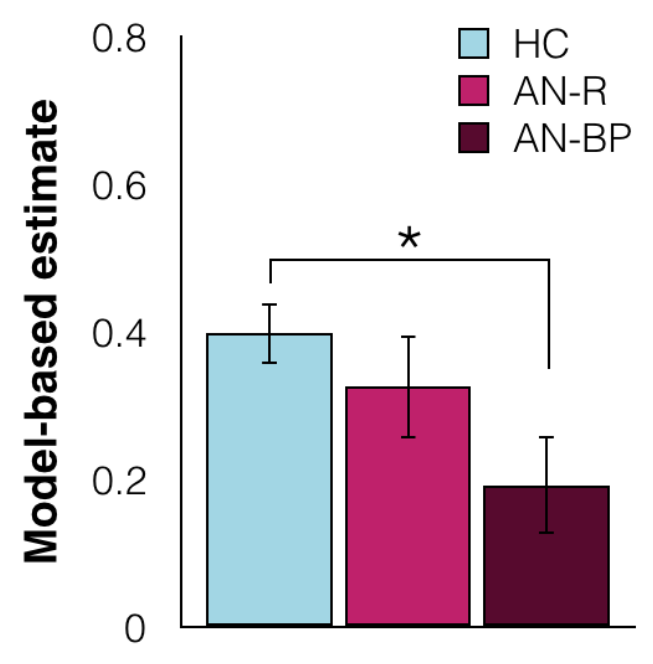

Figure S1: Overall model-free contributions to learning for healthy controls $(\mathrm{HC})$, AN with restricting subtype (AN-R) and AN with binge-purge subtype (AN-BP) across task type (monetary and food) and session (Time 1 and Time 2). 
medRxiv preprint doi: https://doi.org/10.1101/19002089; this version posted July 14, 2019. The copyright holder for this preprint (which was not certified by peer review) is the author/funder, who has granted medRxiv a license to display the preprint in perpetuity.

It is made available under a CC-BY-ND 4.0 International license .

Sub ID:

Date:

Session:

Use the numbers 1-15 to indicate your order of preference for each of these snack items (1=Most preferred, 15=Least preferred)
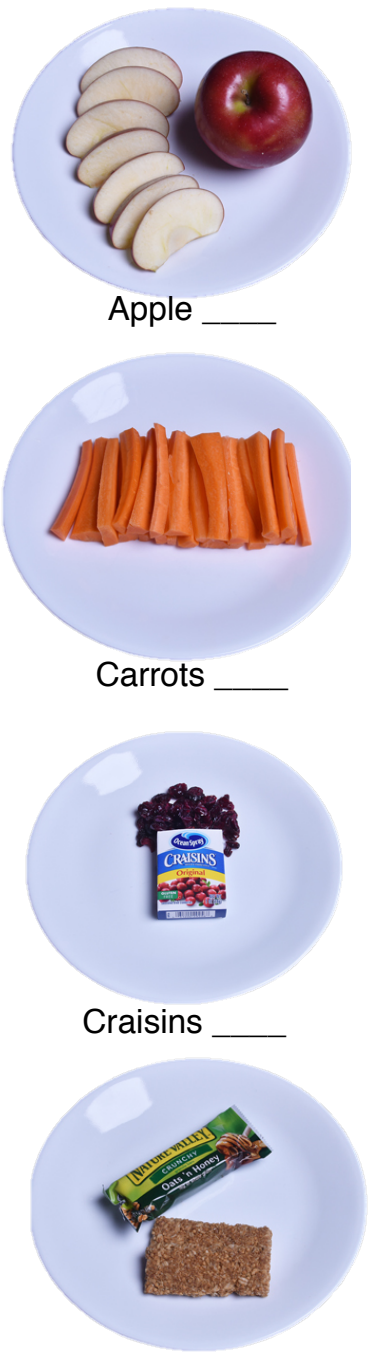

Granola bar

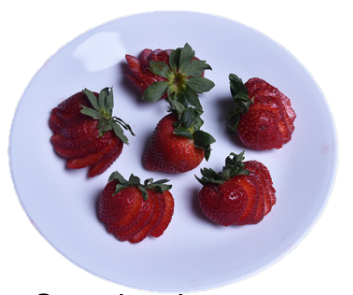

Strawberries
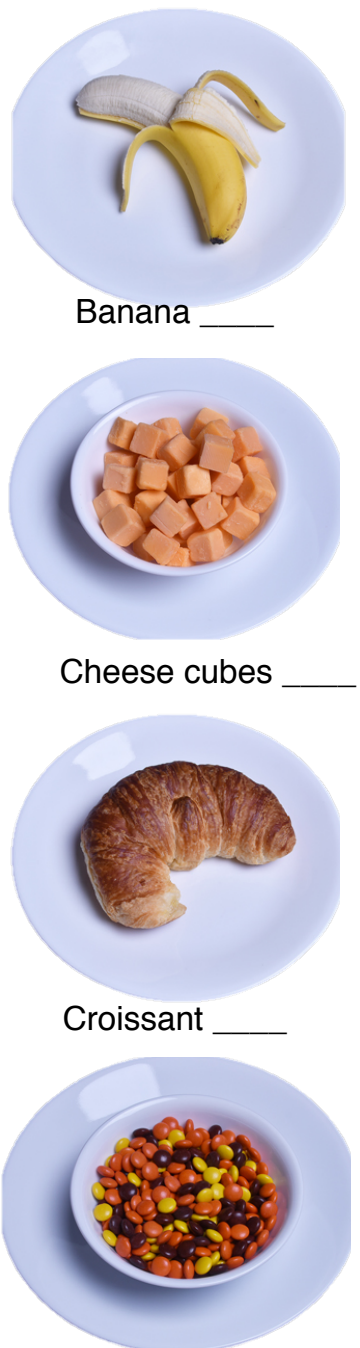

Reeses pieces

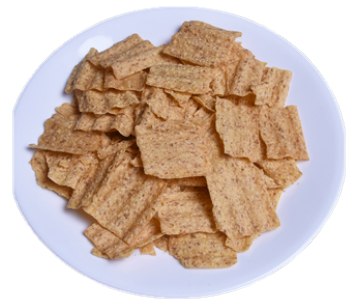

Sun chips

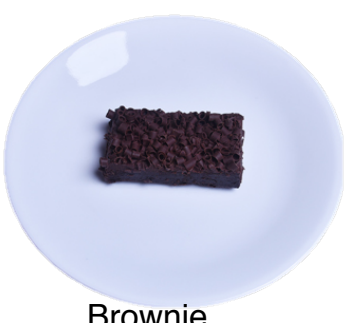

Brownie
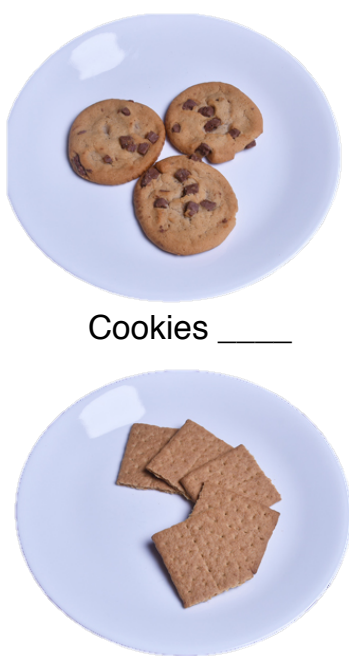

Graham crackers
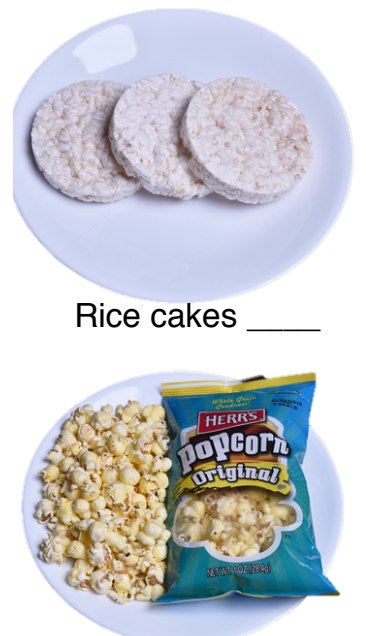

Popcorn

Figure S2: Food task menu used to determine outcomes for the food version of the 2-step task. Participants numbered items in order of preference. Performance on the task determined access to food items, with better performance granting access to increasingly preferred items (see Table S1). 
medRxiv preprint doi: https://doi.org/10.1101/19002089; this version posted July 14, 2019. The copyright holder for this preprint (which was not certified by peer review) is the author/funder, who has granted medRxiv a license to display the preprint in perpetuity.

It is made available under a CC-BY-ND 4.0 International license .

Table S1. Conversion of performance into snack options

\begin{tabular}{|c|c|c|}
\hline \multicolumn{2}{|c|}{ Performance } & \multirow{2}{*}{$\begin{array}{l}\text { Access to snack } \\
\text { item rank }\end{array}$} \\
\hline (proportion correct) & (tokens earned) & \\
\hline$\geq 0.57$ & $\geq 114$ & $1^{\text {st }}$ \\
\hline $0.55-0.569$ & 110 & $2^{\text {nd }}$ \\
\hline $0.54-0.549$ & 108 & $3^{\text {rd }}$ \\
\hline $0.53-0.539$ & 106 & $4^{\text {th }}$ \\
\hline $0.52-0.529$ & 104 & $5^{\text {th }}$ \\
\hline $0.51-0.519$ & 102 & $6^{\text {th }}$ \\
\hline $0.50-0.509$ & 100 & $7^{\text {th }}$ \\
\hline $0.49-0.499$ & 98 & $8^{\text {th }}$ \\
\hline $0.46-0.489$ & 92 & $9^{\text {th }}$ \\
\hline$<0.46$ & $<92$ & $10^{\text {th }}$ \\
\hline
\end{tabular}

